\title{
An Investigation on Painting and Imagery in Zen
}

\author{
Siamak Panahi ${ }^{1}$, Farnaz Cheraghifar ${ }^{2} \&$ Shima Talebian ${ }^{2}$ \\ ${ }^{1}$ Department of architecture, Islamic azad university, Abhar branch, Iran \\ ${ }^{2}$ Master Degree of Architecture, Iran \\ Correspondence: Siamak Panahi, Department of architecture, Islamic azad university, Abhar branch, Iran. E-mail: \\ siamak_architecture@yahoo.com, farnaz.cheraghifar@gmail.com
}

Received: July 9, 2016

doi:10.5539/mas.v12n9p200
Accepted: August 19, 2016

Online Published: August 27, 2018

URL: https://doi.org/10.5539/mas.v12n9p200

\begin{abstract}
This research considers painting and imagery in Zen as an art and its objective is to introduce the influence of Zen on visual arts. The term "Zen" is derived from Sanskrit and it means "thinking". In China and India, Zen Buddhism is known as "Liberated Way of Life" and is strongly influenced by Taoism. It is said that Zen began with an allusion, as one day, instead of preaching, Buddha appeared with a flower in his hand when one of his followers received his speechless message. That was when Zen, with its Indian Dhyāna root meaning meditation, was born.

The research method here is descriptive and analytical with emphasis on inductive approach (checking samples and providing theory).

The resulted process concludes that Zen imagery includes seven principles: asymmetry, purity, stamina, naturalness, deepness, richness and quietism, however; peace or quietism is the concept taken into consideration more than other ones.
\end{abstract}

Keywords: painting, imagery, Zen, minimalism, Buddha

\section{Introduction}

Abandoned in chaotic postmodern world, today's man always dreams of returning; return to self, liberation and relaxed spirit.

Zen frees human from attachments and causes him to achieve their true self and find themselves, regardless of any names and employment or social standings; only true self and how desirable is to see oneself and others, regardless of their position and rank.

Intentions dim friendships... (Rumi, Shams)

The word "Zen" derives from Sanskrit that means "thinking" and it is based on an idea which is Reiki intellectual methods (inner strength) and seeks liberation through "outer aid" (outer power). According to Zen, human is the artist of life.

Zen believes that one should view things without adding to or reducing from them, i.e. we should view things without having to give them more value or reducing from their value. According to Zen teachings, removal of thoughts sticking to mind and concentration are major principles. In this school, "mindful life" is strongly emphasized, which means the ability to feel life at present time that is power to feel "present" and not let future or past affect it. This art of Zen followers and the old Zen school is used a lot in psychology and psychoanalysis and thanks to mindful living, many psychiatric patients are treated, since mindful living gives peace to both patients and non-patients. Zen is a form of sitting which emphasizes moment by moment and deeper thinking of the nature of living things through direct experience.

One day I cleaned up my mind of all thoughts, left all wishes, stopped thinking of all people around and sat in silence. I had a strange feeling as if I was being taken to a place or I had a power which was unknown for myself... I entered a new world. I had lost physical boundaries of my body, I already had skin but I felt as if I was standing at the center of universe. I was talking but words had no meaning. I could see people coming toward me but they were all the same. They were all Me. I had never known this world before. But now I should change my mind. I had never been born. I was the Universe. 


\section{The Emergence of Chan Way (Zen) in China}

Confucianism, Taoism and Buddhism are major philosophical religions in China and according to Bridget Gavignon, they are important inspiring powers in imaginary expression of Chinese art and in technique and character, mind and spirit of the artist. Confucianism was a scientific school developed by Confucius, the philosopher, in China in 479-553 B.C and its goals were benevolence, charity, goodwill, kindness and respect for elders. Taoism was a mysterious mystical school created in China during 400s and 500s B.C by a wise man named Lao Tese focusing on a way of living in harmony with nature. Buddhism was a religion developed by enlightened Buddha who insisted on a simple life and sympathy with all living things and forgetting oneself (Abachi, 2016).

In her book, "Art over Time", Helen Gardner wrote that Buddhism spread to China in the first century when China faced chaos, Confucianism was unable to deal with it and Taoism had drowned in various magic and superstition beliefs (Gardner, 2016).

Therefore, it is obvious that Chinese people and scholars were attracted by new religion of Buddhism, the objective of which was to bring happiness to human and ride him out of sufferings.

In the book "The History of Chinese Philosophy" it is said that during third to tenth centuries, Chinese Taoism and Indian Buddhism dominated Confucianism. Meanwhile, Buddha texts were translated into Chinese and spread in vast proportions and the number of temples and Buddha followers increased quickly. This was until 845 A.D when to the Emperor's command, forty thousand Buddha temples were destroyed and 260000 monks and nuns were expelled from monasteries. However, Buddhism spread until Sung era (960-1279 A.D) when it lost its primary reputation and gradually, a new Buddhism named "Chan" flourished in China which is known as its Japanese name "Zen" (ibid, 2016). Thus, Chan which derives from religious principles of Buddha and Tao doctrine formed in China.

\subsection{Formation of Zen}

Zen Buddhism is an example of what known as "Liberalization" in China and India which is much similar to Taoism. In terms of history, Zen can be viewed as an end and perfection point of far Indian and Chinese traditions (Pezeshki Khorasani, 2016: 85).

It is claimed that Zen began with an allusion when one day Buddha appeared in preaching stand with a flower in his hand and one of his followers received his speechless message and Zen, meaning meditation in its Dhyana Indian root, originated.

It is worth noting that during twelve centuries, Zen has taken deep roots in China, more Chinese than Hindi, and its deep impact is seen in Japan (ibid: 85).

\subsection{Theoretical Principles of Zen as an Art}

\subsubsection{Art}

In scholar's point of view, Zen, per se, is the art of living. Art deals with aesthetics and Zen has developed special aesthetical principles adopted from ontology and epistemology in combination with local traditions and due to its inclusive nature, it has cast shadow on all aspects of Japanese life with deep effects on Japanese architecture and art.

Zen focuses on inner peace and physical comfort which is considered in architecture and Zen arts in form of expansion of inner life in outer world and vice versa and here peace and harmony are emphasized as the main principles of Japanese aesthetics (E'tezadi, 2016).

Prominent manifestation of allegorical or mystical arts of Asia is Chen or Zen in Japan and China in which, the content of an artistic work is landscape or animal or plant life. The same is true for painting, poetry and music in Vishnu, the theme of which is sexual love and Sufi music and poetry in Iran is devoted to praise of inebriation.

Zen is endless. It is demeanor, itself: it is a sharp ascendancy along which nothing keeps the pupil on the move but his faith in his teacher who is a symbol of inner potentiality to actuality. As an artist, the teacher is religious man and as a human, he is an artist who is eying Buddha. Buddha is the ultimate destination (Herrigel, 2013).

The art of Zen is a visual presentation, representing real awakening and dawn of illumination radiated on mind and heart and finally, reaching freedom of soul or nirvana and this is the starting point of Zen way, since there is no end for this ritual and each ending is a beginning. A particular advantage of Zen is its simplicity because Zen is as understandable for a wise thoughtful man as for a layman.

The most precious aspect of Zen is misrepresentation of affairs which human knows as difficulties of life. About release of pain and anxiety, Zen says: "a world filled with synergy purposes and destinations, with no journey 
among these destinations, a world the value of which is that fast reaching to a location will be baseless, devoid of essence and durability (Pezeshki Khorasani, 2016).

Zen contained two procedures: it was both a factor for concentration of its creators and a means to guide those who face with it. Although Zen was so influenced by Confucianism, Taoism and other Buddha sects, it flourished as a distinct culture among scholars, senior, sages and poets. Years after Buddha sects declined in China, Zen remained stable as a pervasive force until fourteenth and fifteenth centuries when new Confucianism which was a combination of Taoism and Zen principles, replaced it (Hosseini, 2005).

Actually, during Tang dynasty in China (618-906 A.D), there was a trinary classification (San P'ing) of painting: divine (sand), deep or mysterious (Miao) and successful or subtle (Nêng). Divine painting requires absolute perfection and represents purpose instead of human art achievements. Miao is such elaborate painting which approaches perfection and Nêng is absolute craftsmanship. There is another classification named extraordinary or supernatural (i) added later, representing Taoist themes which was philosophical or literary type of personal painting. This kind of painting was a major achievement, although professional artists did not work on it and traditional rules were not applied in it. Thus, "i" corresponds very closely with the concept of genius, with all the advantages and limitations (1889, Giles).

The six rules of Xie Hou concerning painting were published in the fifth century for the first time and remain credible to date. Authors from Far East and Europe discussed it in detail and the most disagreements are on Confucius or Taoist interpretation of first rule. The following explanation is directly based on these rules:

1. Soul (ch'i) begins to flow or it revolts (yün) or its consistency or unity (yün) with movement of life

2. Display the skeleton (essence configuration) by brush

3. Create a figure (Shing) similar to the object (natural form, woo)

4. Apply or distribute colors, according to the "kind"

5. Right composition or literally speaking, "design fitting all"

6. Traditional method (ch'uan) or literally speaking, "drawing based on authentic pattern or method"

Among the rules, in terms of metaphysics, first one is the most important dominating all other five which have straightforward meaning. Second rule requires the display of character, rather than appearance. Rules three and four consider size and color as representation tools, rule number five implies to lay the objects represented in proper positions, according to their natural relations, thus it should be distinguished with today meaning of configuration or set design. The last rule requires taking example of ancient masterpieces and adhering to traditional methods and certain rules. These six rules have great affinity with Indian aesthetic theory in this regard but there is no acceptable reason showing that they originate from an Indian origin (Kumaraswamy, 2005).

An additional point about rule six is that spontaneity and improvisation ("sand", "Sohajeh ") of painter can also be considered above and beyond "clear rules", though not against them. According to Bhagavad-Gita, knower of Brahman does not need Vedas, or Saint Agustin said: "love God and do what you wish". However, if pious personality (jivanmukta) or saint, as a noble man, is not worried about their duties, there will be no separation between self and non-self. For true seekers of Yoga, objective and empirical knowledge (Pratiksha) is so that manifestation of realities is not indiscernible from forms known endogenously [reasonable pure form] and this is a proof, not for genius, but for a perfected self with utmost maturity, that is a perfected insight self by which the person observes not only the sensations evolved from objects, but also everything, as it might be, almost with no dichotomy and duality, however, he loves everything the same.

Thus, art converts to perfection in which visual and formal elements come to a compromise with each other and are all eyes. In this rare position, but almost always present, the whole necessity of art fades. Muslim theologians are absolutely right in this case that the only real artist (photographer) is God, Nirmānana-kāraka in Indian Language (Kumaraswamy, 2005).

The term "God", used as metaphor, exists in Christian scholastic tradition; for example, according to St. Thomas Aquinas in theology entries:

Meister Eckhart uses the same concept. Needless to say that "Creation" ("Nirmān̨a", "karma") is a religious translation (bhaktivāda) of a concept referred to in metaphysics and theology by expressions such as manifestation, declaration or distribution (șrști) and in psychology it is "existence" (Utpāda, bhava, yathā-bhūta, ...) which is dependent on secondary or intermediate causes (Kumaraswamy, 2005).

According to Chieh Tzū Yüan, "when painter reaches Divine perfection (sand), an end comes to the matter”. Such 
a conception is also found in the story of Chinese painter, Wu Tao-Tzû. He painted a magnificent landscape of mountains, forests, clouds, birds, people and everything on palace's wall, a copy of world image. While the emperor, his employer, was praising his painting, he pointed at a door on mountain side and asked him to pass through it to see world's wonders. Assuming that the emperor will follow him, Wu Tao-Tzû entered first but the door was closed and the painter was never seen again. As the same way, disappearing of an art work, when attained perfection, is mentioned in other legends in a mythical way, like the myths of dragons which flew from paintings on the wall. The story was told about Chang Sheng Yu, the artist from Liang dynasty (1986, Chatterji).

\subsubsection{Zen imagery}

Shin'ichi Hisamatsu considers seven features for the nature of Zen artistic work and its aesthetic principles, whether it is created by a Zen follower or an artist influenced by Zen teachings. For ease of induction of thought and state purpose and help for a clear understanding in expression of those features, he considered less philosophical aspects. The features include: (Hosseini, 2015)

As figuration of an art work occurs through art image in the artist's mind which can be called "artists' subjective word", figuration of all creatures takes place by God's word. This is why in top decorative works, God's word is mentioned ... the word "God found it pleasant" states God's special satisfaction with His works, such as an artist who is pleasant with their art.

Asymmetry, purity, stamina, naturalness, deepness, richness and quietism

\subsubsection{Asymmetry}

Symmetry is a reasonable form of charm, grace and impression. Logic formalism or combined abstract ideas are the same. Few people regard Japanese as philosophers or thinkers, since their public culture is not enriched with thinking. This way of judgement is formed due to Japanese desire to asymmetry (Suzuki, 2015).

In Zen painting, visual elements are arranged asymmetrically: tree on one side and mountain on the other side. In many cases, part of a picture is even empty, with no element in it, without any damage to the collection or visual expression (Hosseini, 2015).

\subsubsection{Purity}

Zen- oriented mind struggles to keep clean and clear. Thus, it avoids whatever causing anxiety. The doctrine is evident in tea room which is cleared from any intruding object. Ink painting is selected for those clean immaculate places because it is not colorful. Colored paintings, if not by a skilled artist, may cause lack of concentration so that the seeker neglects true understanding of it. A trained painter in Zen doctrine should be able to reveal true colors at the heart of his black ink and show ice colder, autumn leaves more colorful and sea deeper than they really are (Hosseini, 2015).

\subsubsection{Stamina}

In a Zen-inspired art, human is weary but stable who gains wisdom through continuous life experiences (ibid: 69).

\subsubsection{Naturalness}

Being natural, in Zen, does not only mean being simple or innocent; but also an effort to create image, without specific pattern, through consistency of experiencing. When a Zen following painter was asked how much time he had spent to draw bamboo, the wise painter answered: "fifty years and five minutes, fifty years on studying the bamboo and only five minutes to draw it". Naturalness means honesty. In order to understand the art of Zen, one should know the concept of this honesty (ibid: 70).

\subsubsection{Deepness}

The quality considers the nature of Zen as an art. All the layers are not revealed for the observer at first sight. The seeker needs to achieve variable concepts of images. Ink paintings are examples of this type of works, which, despite their small size, contain deep concepts representing unknown world. Dark stains in Zen painters are not eerie confusing atmosphere observed in other Buddhism works. Zen painters' top works include broad layers and concepts which are understood only through meditation and concentration. The best way to attain their concepts is intuition, instead of expert analysis of its elements (Hosseini, 2015: 71).

\subsubsection{Richness}

In a Zen artist's point of view, insisting on any fixed idea is a bulwark against spirit and mind. Such an artist starts without any arrangements or customs to embody their ideas freely. This freedom is effective even in Zen painter's daily work. He is never worried about braking a brush, since, in such case, he will use his finger or stem straw (ibid: 72). 

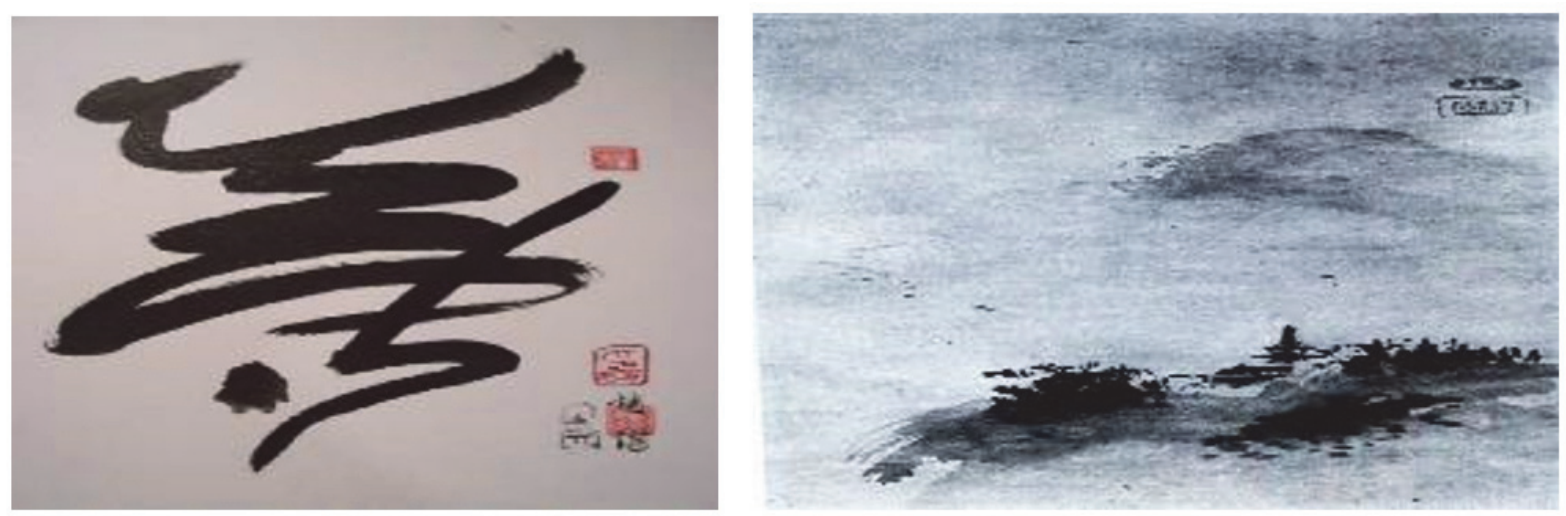

Image 1. Zen paintings

Source: (Hosseini, 2015: 244)

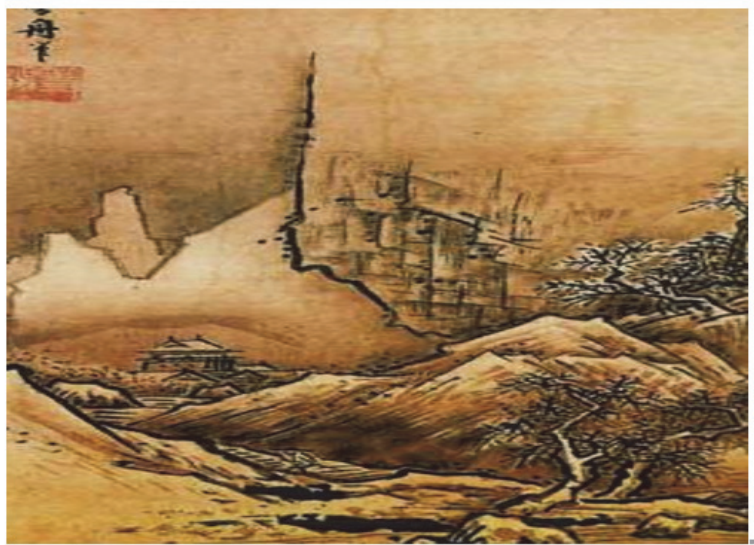

Image 2. winter, by Sosho

Source: Verlag, 1999; 98

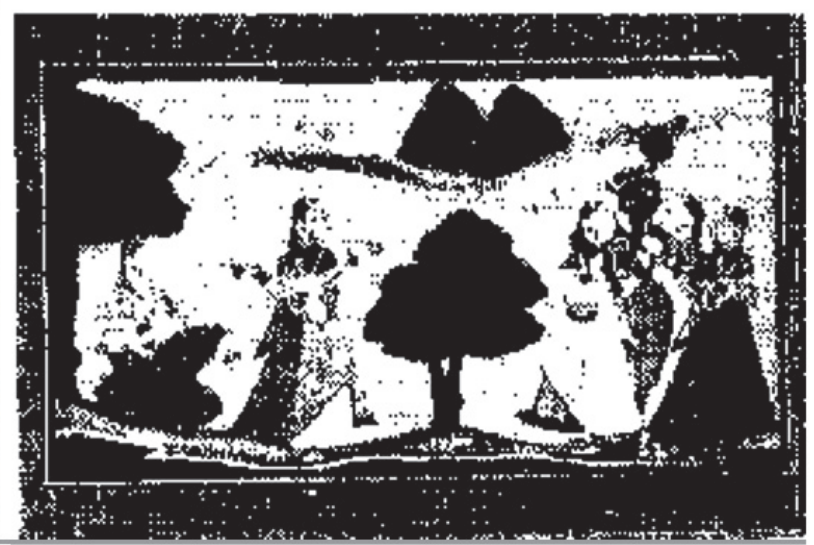

Image 3 . Krishna\& servants, Gita, $17^{\text {th }}$ century

Source: So, 2015; 236

\section{Quietism}

The last feature of Zen painting concerns artist's psyche. In Zen painting, the artist should have a peaceful mind, far from all cares, in revelatory state of meditation, to move like a pen on paper (Hosseini, 2015).

Zen is always known as speechless education, since masters always try to train their followers to achieve illumination so that all limitations of duality of thought and rationality are torn up and they can attain the position. However, if verbal conversation is considered rejected and outcast, how will the doctrine be learned and how will illumination be defined? Speechless education may be interpreted differently: "instrumental use of speech to go beyond the words", about which, Zen masters have penned several books, exactly like Zen advices prescribed for students (Soe, 2015; 234).

Paintings by Zen masters contain a type of duty. There is a straight relationship between patterns and Zen teachings such as theme (outstanding figures and illuminated screens of ascendants) and calligraphic works which appear in short Zen texts and poems. Additionally, a belief has long been in East Asia that said brush and ink represent true nature of artist, therefore, looking at a painting or calligraphy work is a type of relationship with its creator's soul (Soe, 2015).

Those who hesitate and move their brush intentionally to create an image, remain bereft of art (painting, like calligraphy, should be spontaneous and ad hoc). Draw bamboo for ten years and then, when painting, forget whatever you know about them. To gain an error- free technical skill, one should be open to inspiration (Suzuki, 2015).

\section{The Influences of Zen on Painters of South Sung Court}

Buddha Zen (Chan) had its highest influence on the growth of China culture during Southern Sung dynasty. At 
this period young monks were sent from Japan to China to be trained by Chinese masters in monasteries and returned to their country. Thus, many works by Chinese artists and monks came to Japan by Japanese monks during this period, so that a lot of landscape paintings with birds and flowers are found in Japan's treasures and museums (Watts, 2014).

In his work, Zen and Japanese Culture, D.T. Suzuki said that a style named "single corner" began with Mayo Ann.

In this style, sometimes two third of an image is devoted to empty space (vacuity) and the artist uses fewest brush strokes to visualize shapes on paper and this is very harmonious with the spirit of Zen, since Zen seeks for simplicity and avoids mundane and superficial manifestations and complications.

Some outstanding painters in this style are Shiakui, Mayoan, Muchi and Liang Kai. According to Marry Trygear, many artists of Sung dynasty were influenced by asceticism and troubled precise teachings of Chan sect (Suzuki, 2015).

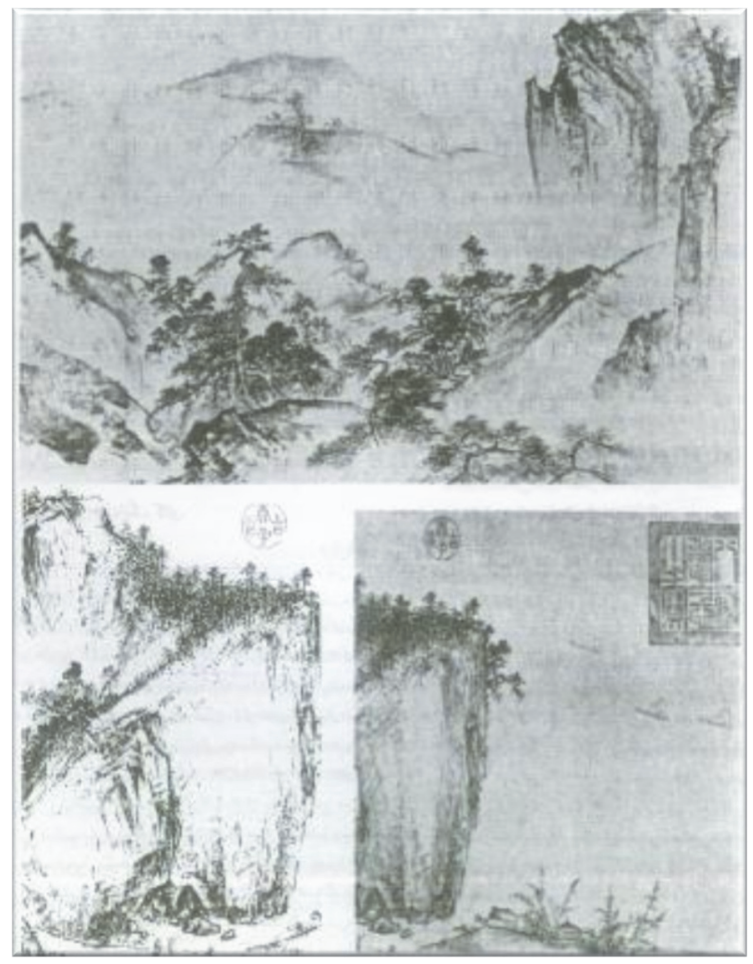

Image 4. Shiakuii, a different open and clear landscape of river and mountain, three components of whole work, hand scroll, ink on paper, National Palace Museum (Abbachi, 2016)

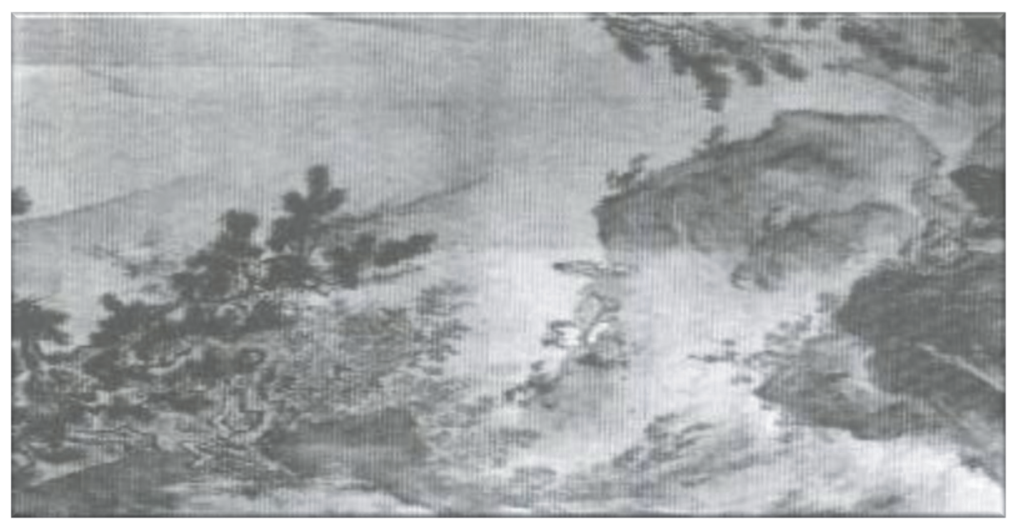

Image 5. Mioan, Moonlight, around 1200 A.D, hanging scroll, ink and color on silk, 2/78 * 7/149 meters, National Palace Museum, Taipei

Image 5 displays one of Mayoan's paintings named "Moonlight". You can see his brush strokes, full of Zen, in 
trunk, branches and needle leaves of an old pine tree, known as "Old Master" which has lowered its head humbly in an atmosphere of silence and a philosopher who is watching nature in moonlight and meditation and thinking.

Moon, tree, servant, philosopher and rock are all one and in harmony, in spite of dominant contrasts (Abachi, 2016). The Old Master is one of Yung's archetypes.

Mocci and Liang Kai are two other painters whose paintings are filled with spirit of Zen. About Mocci's "Persimmon" screen, Marry Trygear noted that "this is a monochromatic painting in shade color. This small screen, reminding color spectrum and paintbrush, represents Chan beliefs". She also said that Mocci might have been a Japanese monk who came to China and joined painters of Sung court (Trygear, 2017).

Persimmons, beyond the theme, is very simply configured, only few persimmons have different colors and sizes, all set in a single line, except one of them which is smaller and set farther. Bold brush strokes in a short time shows immediate and instantaneous reception of theme by the artist. Majority of screen is devoted to empty space around persimmons (Trygear, 2017).

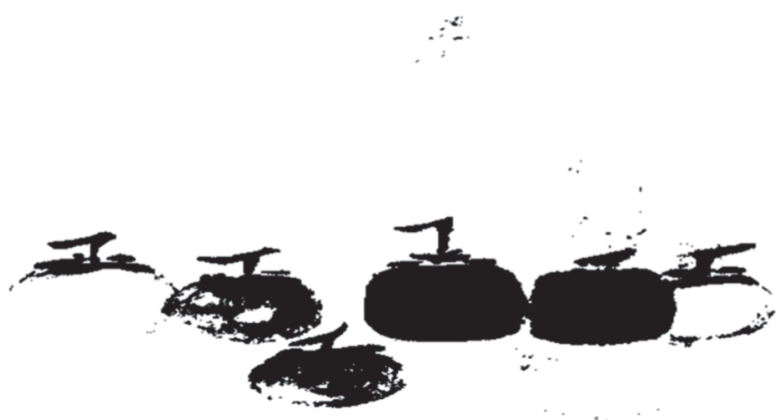

Image 6. Mocci, persimmons, ink on paper

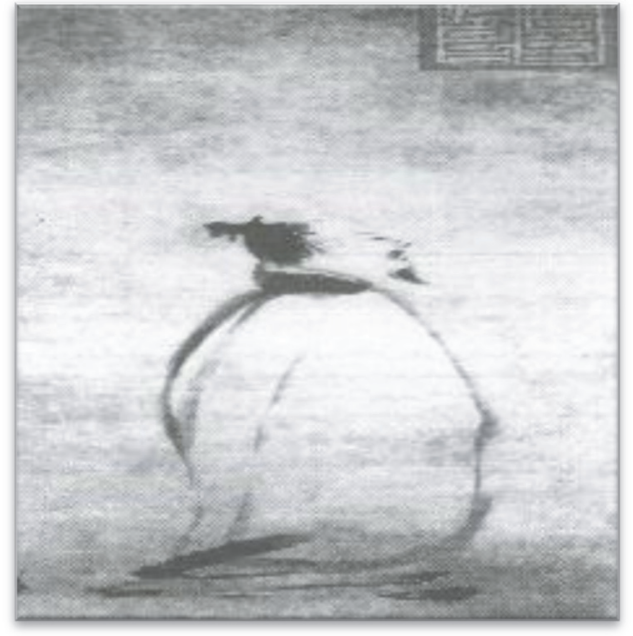

Imge 7. Liang Kai, Li Poi, walking and writing poetry poet, ink on paper

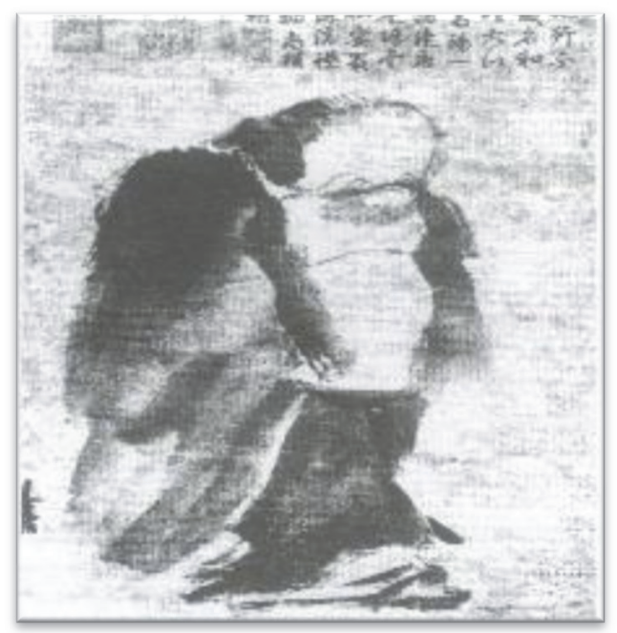

Image 8. Liang Kai, portrait of a clergy man, China, 1200 A.D

Another image displays a screen by Liang Kai named "Walking and writing poetry Li Po, the poet". As is observed, the painter has removed all the details in order to facilitate the receipt of truth of figure. Brush strokes, also, show that the process of Chan's spontaneous enlightenment is sudden and endogenous. Ash forms with a free pen and flowing rhythm explaining artist's intuition and his unification with the theme which is a product of pure soul and free spirit in thoughtless ignored world. In Li Po's face, emptiness of self and sensual desires and a kind of spirituality is felt. He is looking up and away which shows him in a mystical state as if he is deeply meditating. The empty space inside the figure emphasizes on Buddhist impermanence, meaning that everything is empty of a 
sustainable identity and origin. In soul, as well, everything is changing and nothing is stable. A mystical quality of space is felt in this screen. Li Po is vacuity and vacuity is Li Po, there is no separation in between. The attractive fascinating screen is deep, spiritual and supernatural inviting human being to a deep silence and thinking about universe and self.

In another screen by Liang Kai, one can see a Zen master's body and the painter has emphasized his square belly and face in a derisive way. According to Ana Bancroft, the state expresses a depression required to practice Zen (Bancroft, 1979).

\section{Conclusion}

Once the history of painting and drawing are reviewed and it is matched with Zen concepts and seven key concepts of drawing are identified, examples were extracted and used in model 1. Since the seven concepts are used in a different complicated form, it is concluded that quietism and peace is used more than other principles.

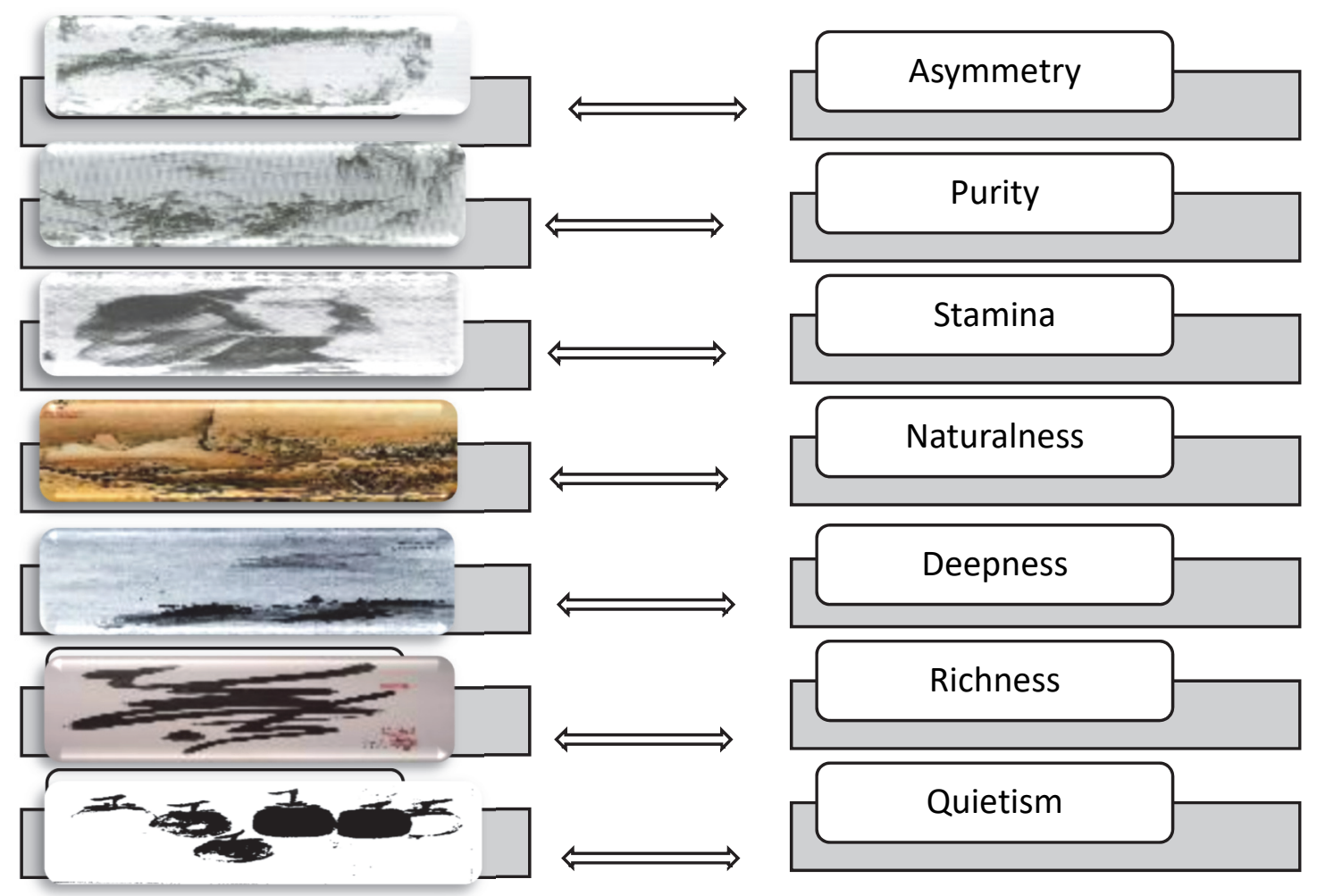

Diagram 1. The relationship between concepts of Zen and Zen paintings

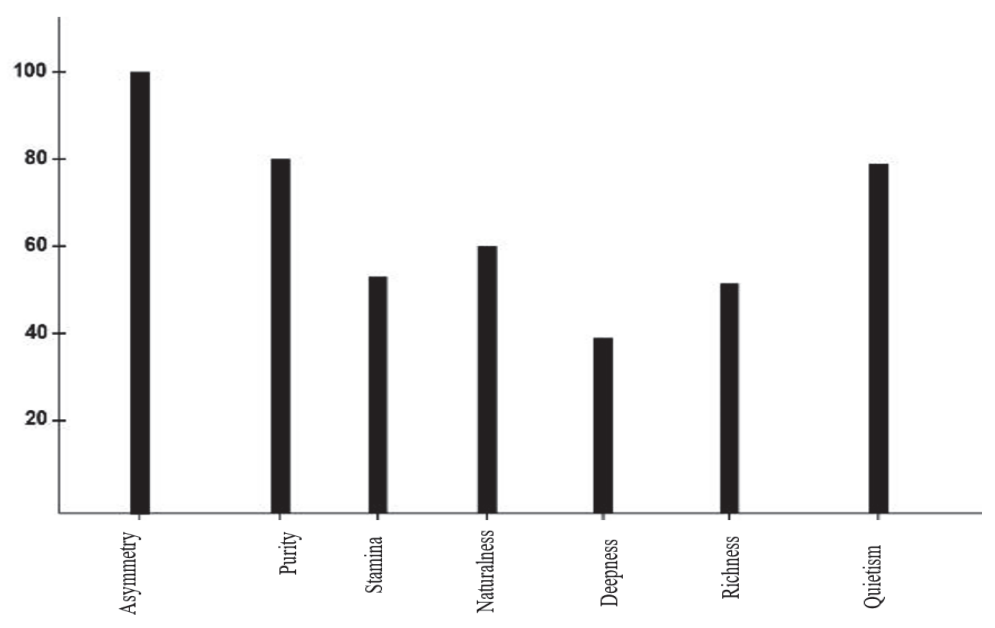




\section{References}

Abbachi, M. (2016). Chan (Zen). Journal of Fine Arts, 18.

Bancroft, Anne. 1979. Zen. Direct pointing to reality. London. Thames and Hudson.

Chatterji, J. C. (1986). Kashmir Shaivaism. Published by State University of New York Press. Albany.

E’tezadi, L. (2016). Soffeh Journal. no 30. Zen and Japanese Architecture.

Gardner, H. (2016). Art over Time. M.T Faramarzi. Journal of Negah. Tehran.

Giles, H. A. (1889). Chuang Tzu. London.

Heriguel, O. (2013). Zen in Archery. Translated by A. Pashaii. Journal of Foroozan. Tehran.

Hosseini, M. (2015). Dao and Painting. Research workshop of visual arts of Asian women, 1.

Hosseini, M. (2015). The Art of Zen. Journal of Art\& Architecture, 30.

Hosseini, M. (2015). Zen in Drawing. Quarterly of Honar-o- Khiyal Academi, 7.

Kumarasuami, A. (2005). Transformation of Nature in Art. Translated by Saleh Tabatabaii. Academi of Art. Tehran.

Naas, J. (2016). Comprehensive History of Religions. Translated by A.A Hekmat. Scientific and Cultural Pubs.

Niktat, H. (2017). Zen Keys. Translated by A. Pashaii. Thaleth Journal. Tehran.

Nitseke, G. (2014). From Shinto to Ando. Translated by A. Amirkhani and P. Baghaii. Journal of Simay-e-Danesh. Tehran.

Pezeshki, K. M. (2016). Zen Thinking and Art. Journal of Art\& Architecture, 47.

Rajabzadeh, H. (2016). Shane thee, Ancient Ritual Japan. Pol-e-Firoozeh Magazine, 4. Office of Cultural Researches in cooperation with International Center for Dialogue of Civilizations. Tehran.

Soe, Y. (2015). Translated by Oormazd. Journal of Literature\& Languages. Bokhara, 32.

Suzuki, D. T. (2015). Henry Corban. Frithof Schwan. Titus Burkhart. Anandak Kumarsi. Researches on spiritual art. Translated by Simin Daneshvar. Hozehonari Pubs. Office of Religious Studies.

Trygear, M. (2017). CHINESE ART. 1924-Rev-ed. London. Thames and Hudson.

Verlag, T. (1999). Japanese gardens (Right Angle and Natural Form). Taschen.

Watz, A. (2014). Zen. Translated by H. Vizheh. Journal of Behjat. Tehran.

\section{Copyrights}

Copyright for this article is retained by the author(s), with first publication rights granted to the journal.

This is an open-access article distributed under the terms and conditions of the Creative Commons Attribution license (http://creativecommons.org/licenses/by/4.0/). 